\title{
"Now I know how to not repeat history": Teaching and Learning Through a Pandemic with the Medical Humanities
}

\author{
$\mathrm{Kim}_{\text {Adams }}{ }^{1} \cdot$ Patrick Deer $^{2} \cdot$ Trace Jordan $^{1} \cdot$ Perri Klass $^{3}$
}

Accepted: 21 October 2021 / Published online: 9 November 2021

(c) The Author(s), under exclusive licence to Springer Science+Business Media, LLC, part of Springer Nature 2021

\begin{abstract}
We reflect on our experience co-teaching a medical humanities elective, "Pandemics and Plagues," which was offered to undergraduates during the Spring 2021 semester, and discuss student reactions to studying epidemic disease from multidisciplinary medical humanities perspectives while living through the world Covid-19 pandemic. The course incorporated basic microbiology and epidemiology into discussions of how epidemics from the Black Death to HIV/AIDS have been portrayed in history, literature, art, music, and journalism. Students self-assessed their learning gains and offered their insights using the SALG (Student Assessment of their Learning Gains), describing how the course enhanced their understanding of the current pandemic. In class discussions and written assignments, students paid particular attention to issues of social justice, political context, and connections between past pandemics and Covid-19. Student responses indicate enhanced understanding of the scientific and medical aspects of epidemics and also increased appreciation of the insights to be gained from the medical humanities. We discuss co-teaching the class during a real-time, twenty-four-hour-news-cycle pandemic, and the ways in which that experience underlines the value of a "critical medical humanities" approach for undergraduates.
\end{abstract}

Keywords Pandemic · Undergraduate education · Medical humanities · Student learning gains

The world Covid-19 pandemic posed challenges at every level of education. For many college students, the spring semester of 2020 involved an abrupt transition to remote learning, and the academic year 2020-21 was profoundly complicated. Some colleges had students on campus and in classrooms, others held no in-person classes at all, and all those which

Perri Klass

perri.klass@nyu.edu

1 College Core Curriculum, New York University, New York, NY, USA

2 Department of English, New York University, New York, NY, USA

3 Arthur L. Carter Journalism Institute, New York University, Department of Pediatrics, NYU Grossman School of Medicine, New York, NY, USA 
did have students present faced the challenges of teaching and learning while testing and tracing and dealing with Covid-19 outbreaks. Many students - like many young people in general - found this a very difficult period with reports of high levels of social isolation, depression, and anxiety (even suicidality) among older adolescents and young adults (Czeisler et al. 2020; Zhu et al., 2021).

For all students, a medical humanities approach offers modes of scholarly inquiry and possibilities for reflection on the complex interplay of biology, narrative, and human history. This multidisciplinary discourse provides ways of considering and reconsidering illness, health, healing, birth, death, and disability. Through the medical humanities, we explore perspectives on human bodies and what becomes of them, and also how human minds formulate and tell those stories individually or collectively. The rich and complex mix of disciplinary approaches and topics, all of them concerned with life and death, sickness and health, suffering and caregiving, may be why the term "medical humanities" has itself been used to mean many different things, ranging from areas of scholarly research to pedagogical approaches designed to enrich professional training in health careers, to selfreflection and emotional support for students and practitioners. An extensive secondary literature now encompasses the medical humanities as a lens for extending and enhancing our understanding of literature, history, and art, and also the medical humanities as an approach to "humanizing" health care by offering students new (and untraditional) tools and skills based in the humanities. Some scholars have called for a "critical medical humanities" approach which emphasizes the intersection of humanities scholarship and social justice, while others feel that "health humanities" better expresses the wide-ranging scholarly possibilities in a field which should not be limited to those engaged in medical training. In the academic setting, debates like these usually indicate robust discourse and widespread engagement - and that was true even before the world became caught up in the pandemic narrative of the novel coronavirus, which brought the medical humanities into the headlines. Every iteration of the news cycle now reminds us of the vulnerabilities of the body, the complexities of social justice and inequity, and the pressing human question of how to understand the story of the times through which we are living.

Beginning in fall 2019, a Medical Humanities Working Group at New York University (NYU) had convened faculty from a wide variety of academic fields with two years of funding from the NYU Center for the Humanities. The goals of the working group were to foster interdisciplinary scholarly exchange and research and to develop an undergraduate minor in the medical humanities at the College of Arts and Science (a Division of Medical Humanities at the School of Medicine is focused on medical student education). As members of this Working Group, we decided to offer an undergraduate course in "Pandemics and Plagues" in the spring semester of 2021, planning to use the multidisciplinary approach of the medical humanities to think with our students about the historical context of past pandemics and about the ways that plagues and pandemics figure in fiction, poetry, and drama. We were aware that our students were facing extraordinary challenges, and we wanted to explore how different forms of scholarly inquiry could inform our experience of living through this unusual semester. NYU did have students on campus, and some classes were being taught in person, but medium-sized courses like ours met remotely.

Early in the course, we acknowledged that while we would be studying different perspectives on the pandemics of the past, we would also be living through a pandemic story together that none of us could predict. When the course first started meeting in early February 2021, vaccines were beginning to be available in New York City (and other locations where many of our students were living) but were not yet being given to healthy young people who were not front-line workers. Vaccine opposition had not yet emerged as the 
critical problem it later became in many parts of the US, and no one had ever heard of the Delta variant. We emphasized to our students that we had no way of knowing what the spring would bring, but we would be studying how the stories of past pandemics have been told and understood, to help us make sense of the unfolding story that included us all (see Lepore 2020).

The course was designed to be interdisciplinary in approach; the faculty members included two instructors with $\mathrm{PhDs}$ in English, one with a $\mathrm{PhD}$ in chemistry, and one with an MD. Guest lecturers included faculty members representing a wide range of fields, including History, Musicology, English and Italian literature, Art History, Journalism, Nursing, and Ethics. To our delight, the course attracted an interdisciplinary mix of students, as described below, and generated substantive discussions - in the virtual classroom and on the page - which helped both students and teachers through that strange pandemic semester.

\section{"Pandemics and Plagues": an undergraduate course for a pandemic semester}

"Pandemics and Plagues" brought together students and scholars from a wide range of disciplines, seeking to integrate historical, scientific, and literary perspectives. We aimed to bring the critical insights of humanities scholarship to bear on the larger social structures that produce, contain, and treat disease. In this regard, our work contributes to the critical medical humanities, a particular subset of the larger field of medical humanities, which uses theoretical discourses like critical race studies, postcolonialism, feminism, and queer studies to analyze systemic inequities in human health. Using seminar style discussion about literature, drama, film, and historical documents, we taught our students and ourselves to approach the structural inequalities laid bare by the Covid-19 pandemic. Our discussions placed the headlines of the twenty-four-hour news cycle in historical perspective and offered the students theoretical tools with which to analyze their own world at this disconcerting moment. We were constantly surprised by the generosity and insight with which students approached complex issues of race, gender, ability, sexuality, and social class in their spoken and written contributions to the course.

"Pandemics and Plagues" was offered as a two-credit undergraduate course, cross-listed in the English and Journalism departments at NYU, open to any interested students and meeting once a week for an hour and a quarter in the Spring 2021 semester. The syllabus drew on the crowd-sourced expertise of our Medical Humanities Working Group and was structured around five two-week units, consisting of alternating presentation sessions and seminar-style discussions of literary and historical texts, movies, and works of art. The course was offered as a co-taught class designed as an introduction to the medical humanities and, more challengingly, as a real-time course about pandemics to be taught remotely due to the exigencies of Covid-19. Given the potentially vast range of topics in the medical humanities, we decided to take a roughly chronological approach over the two-week units: Bubonic Plague; Tuberculosis, Smallpox, and Childhood Mortality; The 1918 Influenza Pandemic; Post-War Anxieties and Polio Vaccination; and HIV/AIDS: Pandemics and Protest. The syllabus also included two one-week sessions, on Syphilis and Women's Public Health in the $19^{\text {th }}$ Century and Covid-19: Reporting on Pandemics Past and Present. Students were introduced to each of our major topics by a session with a course instructor or a guest speaker. During the following week, we offered discussion sessions focused on that 
week's readings, which divided the class in half, each Zoom breakout room led by two faculty members. In addition to the weekly readings, students were asked to write three short "reflection" papers, providing a close reading of a text from the syllabus, and a "synthesis" paper at the end that combined two course readings with their own experiences of the current pandemic. On the weeks they were not writing papers, students were asked to post discussion questions regarding the readings and presentations on the on-line course forum (Fig. 1).

\section{Pandemics and Plagues}

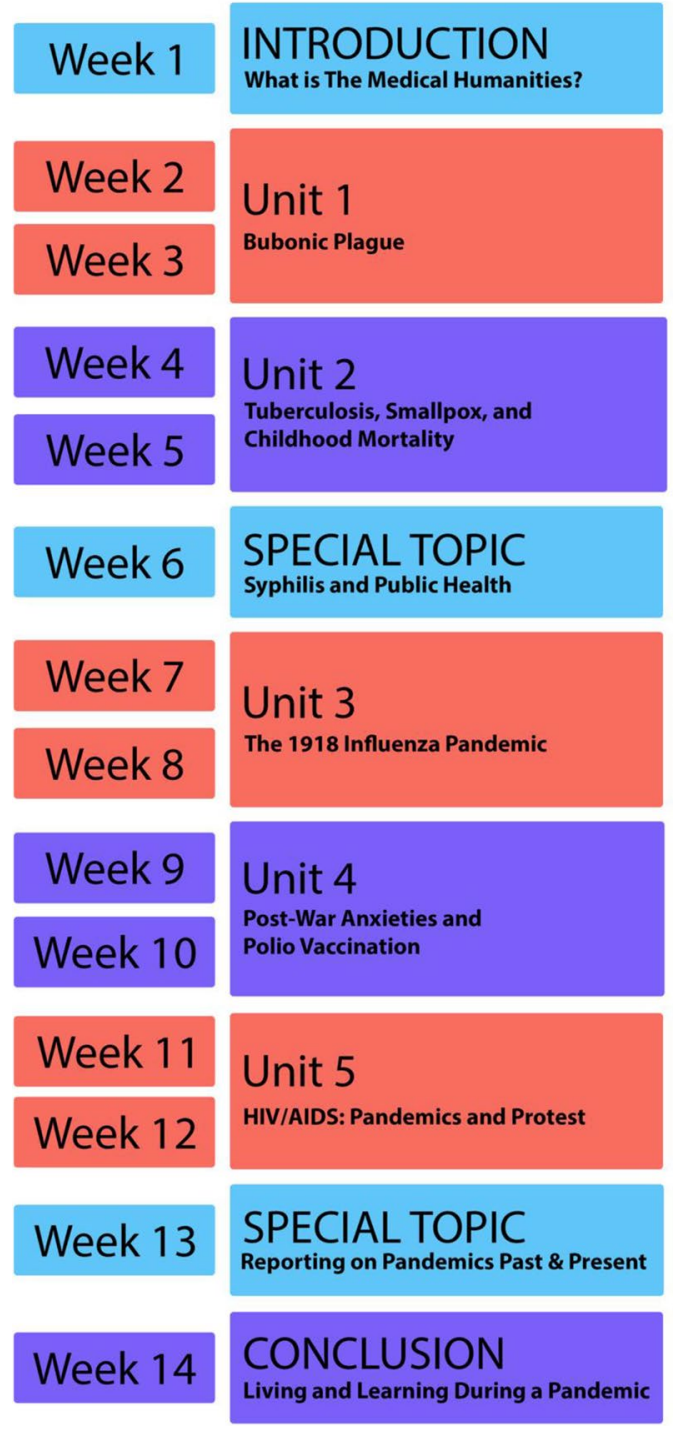

Discussion and Course Planning

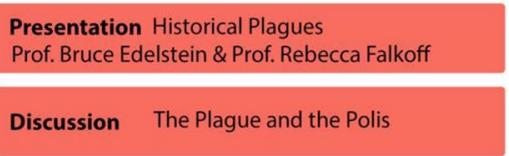

\begin{tabular}{|l|}
\hline Presentation Living to Grow Up \\
Prof. Perri Klass
\end{tabular}

\section{Presentation and Q\&A \\ Prof. Dara Regaignon and Prof. Michael Beckerman}

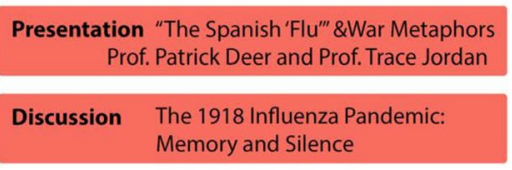

\section{Presentation Prof. David Oshinsky History: Polio, Experimentation, and Vaccination

Presentation Prof. Rebecca Falkoff
Race, Technology, Apocalypse, and Science Fiction

\section{Presentation Prof. Fidelindo Lim \\ Medical, Media, \& Activist Responses to HIV/AIDS}

$\begin{array}{ll}\text { Discussion } & \begin{array}{l}\text { The HIV/ AIDS Epidemic, } \\ \text { Protest, and Activism }\end{array}\end{array}$

Presentation and Q\&A Prof. Ivan Oransky Prof. Art Caplan and Helen Branswell

Discussion Student Reflections on COVID-19

Fig. 1 Pandemics and Plagues Syllabus Infographic 
The chronological and comparative approach to the syllabus provided students without a science background an introduction to the science of each of the historical pandemic and contemporary medical approaches. We took care to contrast what was known at the time about the pandemic with our current medical and scientific understanding of the disease. This gave students a systematic grounding in medical and microbiological knowledge about each historical pandemic as a complement to their humanistic exploration. We discussed the Yersinia pestis bacterium that caused bubonic plague, along with readings from Boccaccio's Decameron and Albert Camus' The Plague; the H1N1 influenza virus for the 1918 pandemic, along with Katherine Anne Porter's Pale Horse, Pale Rider; Mycobacterium tuberculosis along with Eugene O'Neill's play, Long Day's Journey Into Night; the virology of HIV along with the plays and film adaptations of Tony Kushner's Angels in America and Larry Kramer's The Normal Heart. The brief overview of each pathogen informed our readings of these classic literary examples.

As the semester proceeded, the juxtaposition of pandemics and plagues over time allowed for threads and through lines to emerge from the discussion, including science and superstition, attitudes toward contagion and quarantine, racism and xenophobia, inequities in vulnerable populations, and the power of narrative, story-telling, and popular memory. This combination of historical, medical and thematic approaches helped provide students - and faculty - some distance for reflection on the unfolding Covid-19 pandemic. As we had hoped, the alternating rhythm of the syllabus worked well for the four faculty members teaching the course, as we moved from lecturing and moderating discussions with visiting presenters in the first week of each unit to presenting on the readings and leading student discussions in the second. Our overall syllabus design adapted well to teaching on Zoom during the pandemic, and we look forward to future in-person iterations of the class, which have the potential to scale up into larger lecture courses, or scale down into seminars.

\section{Students from across the disciplines and around the world}

One consequence of teaching a course during Covid-19 was the necessity of offering remote classes using the online platform, Zoom. The varied geographic locations of the students who logged onto the weekly Zoom classes reflected the unusual context of teaching and learning during a pandemic. Among the thirty-four students enrolled in "Pandemics and Plagues," eighteen (53\%) were located in New York, with ten students living in a NYU residence hall. A total of sixteen students (47\%) were taking the course from distant locations, located in four states within the U.S. plus Hong Kong and Korea. Among this remote group, four students were participating in NYU's "Go Local" program at the university campus in Shanghai, with a local class meeting time of 11:00 p.m.

The students in the course skewed towards the humanities and social sciences, with only a few students who intended to pursue a career in the health professions. Overall, they represented six undergraduate schools at NYU, with the largest groups from the College of Arts and Science (64.7\%), the School of Liberal Studies (17.6\%), and the Tisch School of the Arts (8.8\%). They included sophomores (29.4\%), juniors (41.2\%), and seniors $(29.4 \%)$. The most popular undergraduate majors were English and American Literature (26.5\%) and Psychology (11.8\%). Only three students declared a major or minor in science, all of whom had chosen to complement their scientific studies with a major or minor in the humanities or social sciences. A total of five students (14.7\%) in the course were participating in the undergraduate pre-health track. 


\section{Their stories: assessing student learning in "Pandemics and Plagues"}

To reveal students' learning experiences in the "Pandemics and Plagues" course, we utilized an assessment instrument called the SALG (Student Assessment of their Learning Gains). The SALG was first developed in 1997 as an innovative strategy for examining student learning that provides more nuanced feedback than the traditional course evaluations (Seymour et al. 2000). After more than two decades of research and refinement, the SALG has been transformed into a sophisticated online assessment tool (www.salgs ite.net; Carroll 2010). Although the SALG has been used primarily for STEM courses, its assessment methodology has broad applicability to a variety of subjects. In essence, the SALG prompts students to provide metacognitive reflections on their learning gains, offering instructors richer insights into the educational impact of a course. The SALG is designed to ensure that all student responses are anonymized; the website assigns a randomized ID number to each student's response so that it is not possible to associate specific survey responses with individual students. By ensuring anonymity, the SALG creates an environment that encourages students to provide authentic feedback about their learning experiences (Jordan 2012). The SALG survey was administered at the end of the semester as an extra-credit assignment. Responses to the SALG were submitted by twenty-eight students, for a completion rate of $82.4 \%$.

An early question in the SALG asked students to explain their motivation for taking the course. Reflecting on their initial decision to enroll in the class, some students recalled how they hoped the course would help them process their personal experiences with Covid-19. "Living in an era of pandemics," one student wrote, "I somehow sensed myself being at a turning point in history. I was quite curious to see how people in the past reflected on similar situations. What did pandemics mean to them? What changes had they brought?" Other students acknowledged their initial fears of engaging with the study of pandemics at a time of personal risk and societal devastation. One student wrote about feeling "the same panic that people globally experienced" during Covid-19, but recognized that the course "would be helpful to understand the history of plagues and pandemics, especially from multiple areas of specialization." Another student originally thought that the course content "might be difficult to think about given the pandemic we are going through right now, but I think it helped me cope with it better somehow." As a final comment, one student succinctly summarized their motivation: "I was interested in learning about pandemics while actually living in one."

As instructors, we had addressed students' concerns explicitly in the first class, pointing out that the course would immerse us all in some of the most painful details of our own pandemic, but that the readings for this class, the presentations and the discussion groups would allow us space to think critically about it. We acknowledged that there might be times when this mode of critical inquiry would be stressful. Our students took it in their stride with remarkable energy and engagement.

Subsequent questions in the SALG were designed to elicit students' reflections on how the course affected their learning gains in four categories:

- Understanding course content

- Increase in skills

- Impact on attitudes

- Integration of learning 
Table 1 Student Gains in Understanding

Question: As a result of your work in this class, what gains did you make in $\quad$ Good Gain Great Gain
your understanding of the following?

\begin{tabular}{lll}
\hline The medical humanities as an area of academic inquiry. & $29 \%$ & $57 \%$ \\
The role of the medical humanities in understanding pandemics and plagues. & $32 \%$ & $50 \%$ \\
The scientific/medical basis of pandemics and plagues. & $32 \%$ & $39 \%$ \\
\hline
\end{tabular}

Table 2 Student Gains in Skills

\begin{tabular}{lll}
\hline $\begin{array}{l}\text { Question: As a result of your work in this class, what gains did you } \\
\text { make in the following skills? }\end{array}$ & Good Gain & Great Gain \\
\hline Analyzing a text in the context of the course. & $46 \%$ & $21 \%$ \\
Analyzing film, video, or music in the context of the course. & $39 \%$ & $21 \%$ \\
\hline
\end{tabular}

Table 3 Student Gains in Interest

\begin{tabular}{lll}
\hline $\begin{array}{l}\text { Question: As a result of your work in this class, what gains did you } \\
\text { make in the following interests? }\end{array}$ & Good Gain & Great Gain \\
\hline Interest in pandemics and plagues. & $29 \%$ & $36 \%$ \\
Interest in learning more about pandemics and plagues. & $18 \%$ & $50 \%$ \\
Interest in the medical humanities. & $32 \%$ & $36 \%$ \\
Interest in taking additional courses in the medical humanities. & $25 \%$ & $36 \%$ \\
\hline
\end{tabular}

Table 4 Student Gains in Integration of Learning

\begin{tabular}{lll}
\hline Question: As a result of your work in this class, what gains did you make in & Good Gain & Great Gain \\
integrating the following? & $29 \%$ & $39 \%$ \\
\hline Connecting different topics within the course. & $25 \%$ & $32 \%$ \\
Connecting the content of the course to your major or minor. & $29 \%$ & $50 \%$ \\
Connecting the content of this course to your experiences of living through & & \\
COVID-19. &
\end{tabular}

Within each category, some survey questions asked students to assess their own learning gains by answering questions with Likert scale responses, ranging from "no gain" to "great gain." Student responses to these questions are summarized in Tables 1, 2, 3 and 4, which provide the percent responses for the highest two gain scores. Other questions for each learning category prompted students to provide written reflections on their learning, which we discuss below. 


\section{Increasing understanding}

As shown in Table 1, students reported major gains in their understanding of the medical humanities. Among the respondents, 57\% reported a "great gain" in their understanding of medical humanities as an area of academic inquiry, and 50\% reported a "great gain" in understanding the role of the medical humanities in thinking about pandemics and plagues. Students also reported improved understanding of the scientific/ medical basis of pandemics and plagues, with 32\% indicating a "good gain" and 39\% a "great gain." This survey result supported our decision to integrate a scientific and medical component into our presentation of each plague and pandemic.

Several student comments described how the humanities provide a perspective on pandemics and plagues that complements the conventional medical descriptions: "I experienced firsthand using literature (a humanities subject) to understand pandemics (a medical subject). We frequently engaged in both literary and medical ways of thinking about pandemics and plagues." Other students considered the nature of the medical humanities: "My understanding of the medical humanities is much more rich and nuanced than it previously was. I was unsure as to how the two opposing fields worked together. I now have a better understanding of how the medical humanities play a role in understanding the present moment as well as historically."

When students reflected on their changed understanding of pandemics and plagues, they frequently referenced how the historical framework of the course showed that Covid-19 is just the latest pandemic in a long list of medical misfortunes. One student noted that "Covid is the first pandemic we have experienced," but through taking the course "I was able to see how previous pandemics and plagues have affected other societies." Students also observed recurring themes in society's response to plagues, such that the "history of pandemics and plagues tends to repeat itself, and society seems not to learn from past outbreaks. What the world is experiencing now is not historically unique," or, in the words of another student, "I realized that the problems we are facing now under Covid are not that different." Student responses also expressed greater appreciation of the multifaceted complexity of pandemics: "I thought the study of pandemics to be mostly about medical knowledge," but "the course has guided me to consider the societal implications and effects of pandemics."

\section{Developing skills}

The course modeled the methods of critical analysis in the medical humanities and asked students to apply them to multiple sources. In discussion sections and in response papers, they were asked to analyze literary texts ranging from Boccaccio's Renaissance tales to 20th-century works of science fiction, along with filmed dramatic works and music which referenced epidemic diseases. In order for students to understand the wartime context of the 1918 influenza pandemic, they read World War I poetry by combatant poets and women civilians and accounts of nursing by Vera Brittain and Mary Borden. For the discussion of tuberculosis, we organized an online student watch party for the 1962 film adaptation of Eugene O Neill's play, Long Day's Journey into Night. For the course unit on HIV/AIDS, students watched the HBO adaptation of Tony Kushner's Angels in America. One of the guest lecturers in the course discussed the connection between syphilis and Czech classical music. Course assignments were designed to 
promote close analysis of these sources, with students submitting discussion questions or a two-page reflection paper for each unit.

Table 2 presents students' evaluation of their gains in skills during the course. For analyzing a text, $46 \%$ of students reported a "good gain" and $21 \%$ a "great gain." The responses for analyzing film, video, or music were somewhat lower, with $39 \%$ of students reporting a "good gain" and $21 \%$ a "great gain." The difference in student confidence about their analytical skills may reflect the content of the syllabus, which focused mostly on texts, or it may also reflect the educational background of the students, many of whom were majoring in English and American Literature. When asked to reflect on what skills they gained, students often identified the value of analyzing literary and other texts in their historical context. As one student noted, "this course has allowed me to read texts as representations of their respective time periods. I have also been able to make connections across various time periods and the present." Another student "learned to engage with the historical background while reading a text." Other comments mentioned "close reading" as a skill developed during the course. A student reported that "I was able to gain more analytical skills when it comes to digging through details in a text," while another noted how "this class taught me to focus on analyzing textual evidence as the basis for my argument in a paper."

\section{Gaining interest}

There is a growing body of research on the development of interest as a motivational factor in learning (O'Keefe and Harackiewicz 2017). The SALG survey was designed to give us a glimpse of our students' interest and the development of their motivation within and beyond the course. The survey aimed to distinguish between two types of interest: Gains in interest as a result of taking the course, and the generation of interest to pursue further study of pandemics or the medical humanities. Based on the results in Table 3, 36\% of students reported a "great gain" in their interest in pandemics and plagues, and $50 \%$ of students indicated a "great gain" in their interest in learning more about this topic. With respect to the medical humanities, $36 \%$ of students reported a "great gain" in their interest, with the same percentage expressing an interest in taking further courses, though one student noted: "I don't think I want to discuss this topic much further because of how exhausted I am by the current pandemic." In their written comments, other students identified a newfound interest in the medical humanities. For example, one noted that "it was a completely new subject for me to think about the medical humanities" and "diving into this class really helped me...consider it as something I'd love to pursue in the future." For another student, "the course has given me many starting points to start my own thinking, research, and learning of the medical humanities." These comments generally support our educational objective of using "Pandemics and Plagues" as a timely gateway course to stimulate students' interest in the medical humanities.

One question in the SALG survey asked students to identify the most interesting course topic, and over half of the respondents selected HIV/AIDS. While the emergence of the global AIDS pandemic is a vivid memory for the course instructors, it felt far removed to many students. "I had minimal experience with this topic previously," wrote one student, "and learning about it through the medical humanities really enlightened [me]." Another student "was surprised by how little I knew about this epidemic outside of the pathogen that we learn in biology courses." Similarly, many students identified the material about HIV/AIDS as the most interesting reading or film in the course. One student reflected that The Normal Heart "offered so much information and insight about the HIV/AIDS 
pandemic," while another student found "the fictional representation of real struggles of real activists to be both interesting and moving."

\section{Integration of learning}

The medical humanities is an inherently integrative endeavor, seeking to explore the human experience of health and disease through literary and artistic expression. The "Pandemics and Plagues" course examined these interconnections through the selection of texts, film, and music. As a result, we were particularly interested in what students gained through an integration of their learning. According to the results in Table 4, 39\% of students reported a "great gain" in their ability to connect different topics within the course. Many student comments identified common themes that connected various pandemics in different historical periods. One student identified "social injustice and its influence on a pandemic" as a central theme in the course, which is a topic we explore later in this article. Other themes noted were that "all the plagues and pandemics share many elements, especially the loss of identity" and "the connection that vulnerable populations are always the first to be afflicted by disease in large proportions."

Based on the survey results, $32 \%$ of students reported a "great gain" in their ability to connect the content of the course to their major or minor. "As an English major," one student wrote," I was able to interpret literary texts as historical representations of pandemics." A student majoring in psychology remarked on "the psychological effects of plagues... and their long lasting mental effects." A pre-medical student reflected that the course "showed me how as a future medical professional I can think about these diseases outside of their statistics" and instead view them "through their larger impacts on the communities affected."

When students were asked about connecting the content of this course to their experience of living through Covid-19, 50\% reported a "great gain" in making this integration. Many students identified the value of historical context in framing their personal experiences. "As a result of this class," one student wrote, "I was able to see how similar all pandemics and plagues have been through history [and] how they directly connect to what we're all experiencing with Covid-19 right now." Other students agreed: "I was able to make more sense of this moment in time through representations of other plagues," and "I understood we are not alone in our experiences." Some students used specific references to course texts when making a comparison to Covid-19: "The conspiracy theories... in Pale Horse, Pale Rider...reminds me of the role conspiracy theories have played in the current perception of COVID-19 and the vaccines." Another student identified the connection between Boccaccio's Decameron and "the different ways people dealt with isolation... during Covid-19." In drawing such connections, students participated in the integrative, interdisciplinary project of the medical humanities.

\section{Discussion: on living in interesting times}

\section{Interdisciplinary insights}

The final question of the SALG survey asked students to share "one important insight" they gained from the Pandemics and Plagues course. This question repeated a practice that we used in the online classroom: each week at the end of class we asked students to share 
one "takeaway" in the chat, allowing those who were less comfortable speaking on Zoom to communicate their thoughts with the group. In the survey, student reflections followed the pattern of critical engagement we saw in the classroom, drawing connections between the past, present, and future of human health. One student wrote that "throughout the pandemic now, everything felt brand new and overwhelming" but our course helped put the uncertainties of the current crisis in perspective; "I feel I have a better understanding of the rights and wrongs in a climate like this." Another noted: "History repeats itself unfortunately, and there are many more pandemics to come." In this section, student reflections tended towards the sociological rather than the personal - "Plagues and pandemics do not exist in a vacuum and they reflect the society that experiences them" - and the existential - "Question everything." For that we can thank Camus.

Students often positioned themselves as collaborators in the classroom, using the pronoun "we" to describe their experience: "We frequently engaged in both literary and medical ways of thinking about pandemics and plagues, and understood the diseases we studied through a literary lens." The sense of collaboration extended to the course content, which, in the words of one student, "taught me how to engage with both science, medicine, and texts comparatively." Drawing from the survey results, we can see that this interdisciplinary mode of learning empowered students to move outside their familiar patterns of thought. Using their knowledge of literature, culture, and history, students wrote about Yersinia pestis and the polio vaccine, influenza and HIV, topics they had previously considered the exclusive domain of science, and perhaps off-limits to them as humanities majors. This newfound humanistic viewpoint was not only "refreshing and holistic," as one student noted, but also necessary for approaching the social, political, and economic complexities of our current moment.

\section{Social justice and history}

One of the most striking features of students' written comments was their engagement with questions of social justice and history. The syllabus was consciously designed to address the ways that medical and public health approaches, as well as larger societal responses to historical pandemics, have been shaped by questions of race, class, and gender. This was given additional urgency by the heightened and brutal impact of Covid-19 on poor, marginalized, and disenfranchised communities in the United States, and particularly on communities of color. These striking inequities were searingly evident in New York City at the height of the first wave of the pandemic in March-April 2020, and a year later, as we taught the course, we were all aware of mounting evidence of continuing disparities. Students showed themselves to be strongly engaged with the global impact of Covid-19, noting that the roll out of the vaccines in the spring of 2021 was sharply uneven in the US and Europe compared to countries in the Global South. Many of our students were also strongly aware of the so-called "racial reckoning" provoked by the Black Lives Matter protests in summer 2020. This gave the historical dimensions of the course strong resonance, and related issues came up regularly in discussions of human behavior and social class during the time of the Black Death, for example, or in considering how racial segregation affected childhood mortality, tuberculosis, and polio in the United States in the $19^{\text {th }}$ and early $20^{\text {th }}$ centuries.

The course didn't shy away from the politicization of the pandemic by the Trump administration, and we found an emphasis on the scientific and medical approaches to earlier pandemics and the importance of learning from the past helped ground and moderate our discussions. In their written assignments, students often noted the role of governments 
in managing past pandemics, from the failures of the Health Tribunal in 17th century Milan (we read an excerpt from Alessandro Manzoni's historical novel, The Betrothed) to the complex political dramas around HIV/AIDS in late 20th century New York (The Normal Heart and Angels in America were among the students' favorite texts). Questions of social justice were also given a powerful urgency by the appalling rise in racist anti-Asian harassment and violence during the pandemic, which were being discussed as issues of daily life for students based in New York. This was an issue that resonated powerfully with NYU students, who include many Asian Americans and international students from Asia.

Students thus understood the humanistic knowledge they gained to have immediate bearing on the difficult political problems of their own times. As one student wrote in a SALG response: "With the recent rise in attacks on Asian American communities, seeing how other pandemics manifested helped me to contextualize the violence based in fear." Themes of violence, inequity, and injustice appeared as frequently in student writing as they did in the survey, reflecting not only students' political commitments but the entanglement of medical knowledge with the social practices that they encountered in the course material. This recognition put students in "the complex role of critical collaborator" described by Viney, Callard, and Woods (2015) in their article on "critical medical humanities" which emphasizes not antagonism or opposition between medicine and the humanities, but productive entanglement.

While the course aimed to give our students the broadest possible introduction to the subject, our focus as faculty and the students' own interests intersected strongly with this theoretical approach. As Adams and Reisman recently wrote, "A critical medical humanities moves beyond empathy and wellness to prioritize the intersection between humanities scholarship and social justice" $(2019,1404)$. Medical humanities, in this sense, is not the handmaiden to the medical sciences, teaching better bedside manner or alleviating burnout. Instead the interdisciplinary strategies of critical theory serve to recognize societal pressures shaping human health outside the clinical encounter. If racial violence against Asian Americans in our current moment is a repetition of violence against marginalized communities in prior moments of pandemic fear, a course like "Pandemics and Plagues" can teach us about the connection between biomedical threats and the persistent structures of human social organization.

In their final response papers, students were asked to connect two or more of the course readings with their own experiences of Covid-19. Many commented on the politics of stigma, connecting the Victorian Contagious Diseases Act, which targeted female sex workers, to the early US government response to HIV/AIDS, which framed it as the "gay cancer." Students saw these historical moments reflected in contemporary political rhetoric, which named Covid-19 the "China virus," and politicized mask mandates, sometimes to the point of endangering essential workers. Others wrote about the need for connection in times of crisis and the loneliness of pandemics, which translates from the fever dreams of Katherine Anne Porter's classic novella of influenza, Pale Horse, Pale Rider, to the isolated hospital wards of AIDS patients in Angels in America, to our own experiences of social distancing and isolation during Covid-19.

For many students, "Pandemics and Plagues" was an introduction to the field of medical humanities. Encountering this growing interdisciplinary field during a pandemic shaped the learning environment by moving our classroom onto Zoom and making our discussions resonate with the news. As we learned from the SALG responses, the pandemic certainly guided our students' interest in the subject matter, and their engagement with the course materials. In this context, students kept returning to social and political concerns. In writing and discussion, they connected individual political commitments and personal 
experiences to analytical tools from a range of disciplines which allowed them to approach challenging subject matter confidently, material made even more daunting by its relevance to their - and our - current pandemic moment.

Medical humanities courses are often pitched at students who are already pursuing medical and scientific education, particularly students on the pre-health track. The enrollment of students pursuing degrees in the humanities, and their heartfelt, vigorous - and intellectually rigorous - participation in the course during the third semester of online coursework, when burnout was rampant, revealed to us a broader potential for medical humanities pedagogy. Students enrolled in this course because Covid-19 altered their worlds - and their college experience. We taught the course because we knew that a critical framework of humanistic inquiry was necessary for understanding the global changes wrought by the novel coronavirus pandemic. We hope that this course can serve as a model for future courses at NYU and beyond, and that these courses will expand the scope of medical humanities education to include a greater focus on social justice-reflecting the importance of understanding the social determinants of health; the value of analyzing the stories we tell about pandemics; the potential of different critical approaches to broaden our understanding of epidemic disease; and the clear urgency of student interest.

\section{Conclusion: teaching and learning through a pandemic}

To study pandemics and plagues and the ways that they figure in human narratives, while at the same time living through a pandemic and thereby taking part in that real-time narrative, places both students and professors in an interestingly "meta" situation for teaching and learning. The same could be said of students of medicine, nursing, or public health, whose training was both interrupted and forever changed by the circumstances of the novel coronavirus. In using the many lenses of the medical humanities to explore both pandemics past and pandemic present with a group of undergraduates, we found that students were often specifically eager for precisely the interdisciplinary opportunity to incorporate scientific and medical information with perspectives drawn from the humanities. They were also eager both to consider issues of social justice, health equity and inequity, and government responsibility, and to explore the power of literature and narrative to comprehend, heal, and divert readers and audiences in times of pandemic crisis. They found that insights from history, literature, drama, art, and music could contribute to this discourse in meaningful ways.

In planning and teaching the course, and then reacting to events as they happened, we as faculty members inevitably found ourselves talking about the times through which we were living - and teaching. In reviewing the stories of the Black Death, of polio, of the 1918 influenza pandemic, of tuberculosis, and of HIV/AIDS, we found new and often unexpected connections, parallels, and insights, and so did our students. Given the challenges of this diverse subject matter, co-teaching the course with faculty trained in medicine, science, and literature helped us provide a richly interdisciplinary framework for our students. Co-teaching, like the collaborative ethos of the medical humanities, also helped sustain us as fellow scholars, teachers and colleagues confronting the human challenges of the ongoing pandemic. The course was never centered on Covid-19, but there was no discussion which ever left it completely behind, and everyone was aware of a strong sense of immediacy and relevance. 
Along with everyone else in the world, we found ourselves living through a global pandemic in the spring of 2021. As faculty members who had already been participating in regular discussions of the medical humanities, and what they might add to undergraduate education, we created a course which offered undergraduates perspectives from history, literature, and other disciplines in the humanities. We thus found ourselves teaching pandemics through a pandemic, discussing topics which were closely related to the content of the twenty-four-hour news cycle from perspectives which take a much longer view. The class became for us, and for our students, a way of exploring these fields that felt directly connected to our daily lived experiences, and that provided intellectually satisfying opportunities to examine great works of literature and drama as matters, quite literally, of life and death.

The field of the medical humanities is sometimes treated as potentially therapeutic, whether expected to improve patient healing or asked to provide health care workers with respite, reflection, or even, again, healing. Our intent in teaching this course was distinctly not therapeutic, in that we were deliberately inviting students to encounter material which might potentially reinforce their fears and anxieties about infectious diseases and their potential to destabilize society, exacerbate social injustice, and ravage the vulnerable human body, as well as the body politic. It would be perfectly understandable if students whose lives had been disrupted by one virus might not want to devote their academic energies toward understanding what other viruses and bacteria can do. But it was clear that for the students who signed up for the course, the scholarly rhetoric of the humanities fields, applied to these topics, served both intellectual and emotional purposes. Boccaccio's group of noble youth in the Decameron retreated from the plague-ridden city to tell stories which were not about the plague, which helped pass the time, as they waited for the disease to pass them by. Our students took another approach, also centered in narrative and story, as they looked closely at the pandemics of the past, and at the ways that artists and writers (including Boccaccio) and scholars have approached those outbreaks. Teaching and learning about pandemics meant considering carefully together the different ways that human beings have found to understand and describe our most traumatic interactions with the microbes which affect us and infect us, paying attention to the science and the story-telling, both fields which reflect endless human ingenuity, even in the face of darkness and disease.

Acknowledgements The authors gratefully acknowledge the support of the NYU Center for the Humanities, which funded the Medical Humanities Working Group, with special thanks to Ulrich Baer and Molly Rogers. Saronik Bosu served as project coordinator for the Working Group. We are especially grateful to our colleagues who contributed to the "Pandemics and Plagues" course, including Michael Beckerman, Helen Branswell, Arthur Caplan, Bruce Edelstein, Rebecca Falkoff, Ernest Gilman, Fidelindo Lim, Ivan Oransky, David Oshinsky, and Dara Regaignon. Finally, we wish to thank the students in the course for their thoughtful participation and insightful reflections.

\section{References}

Adams, Zoe, and Anna Reisman. 2019. "Beyond Sparking Joy: A Call for a Critical Medical Humanities." Academic Medicine 94:1404. https://doi.org/10.1097/ACM.0000000000002871.

Carroll, Stephen B. 2010. "Engaging Assessment: Using the SENCER SALG to Improve Teaching and Learning." In Science Education and Civic Engagement: The SENCER Approach, ed. Richard Sheardy, 149-166. Washington, DC: American Chemical Society, ACS Symposium Series.

Czeisler, Mark É, Rashon I. Lane, Emiko Petrosky, Joshua F. Wiley, Aleta Christensen, Rashid Njai, Matthew D. Weaver, Rebecca Robbins, Elise R. Facer-Childs, Laura K. Barger, Charles A. Czeisler, Mark E. Howard, Shantha M.W. Rajaratnam, 2020. "Mental Health, Substance Use, and Suicidal Ideation 
During the COVID-19 Pandemic - United States, June 24-30, 2020.” Morbidity and Mortality Weekly Report 69:1049-1057. https://doi.org/10.15585/mmwr.mm6932a1.

Jordan, Trace. 2012. "Using the SENCER-SALG to Reveal Student Learning in a Large-scale Environmental Chemistry Course for Non-majors." In Science Education and Civic Engagement: The Next Level, ed. Richard Sheardy and David Burns, 179-215. Washington, DC: American Chemical Society, ACS Symposium Series.

Lepore, Jill. 2020. "What Our Contagion Fables are Really About." New Yorker, March 23, p. 22-25. https://www.newyorker.com/magazine/2020/03/30/what-our-contagion-fables-are-really-about. Accessed October 12, 2021.

O'Keefe, Paul A, and Judith M. Harackiewicz, eds. 2017. The Science of Interest. Switzerland: Springer International Publishing.

Seymour, Elaine, Douglas J. Wiese, Anne-Barrie Hunter, Susan M. Daffinrud. 2000. “Creating a Better Mousetrap: On-line Student Assessment of their Learning Gains.” https://salgsite.net/docs/SALGP aperPresentationAtACS.pdf. Accessed September 8, 2021.

Viney, William, Felicity Callard, and Angela Woods. 2015. "Critical Medical Humanities: Embracing Entanglement, Taking Risks.” Medical Humanities 41:2-7. https://doi.org/10.1136/medhum-2015-010692.

Zhu, Kevin, Zhongzheng Niu, Jo L. Freudenheim, Zuo-Feng Zhang, Lijian Lei, Gregory G. Homish, Ying Cao, Shauna C. Zorich, Yihua Yue, Rujie Liu, Lina Mu. 2021. "COVID-19 Related Symptoms of Anxiety, Depression, and PTSD among U.S. Adults.” Psychiatry Research July (301): 113959. https:// doi.org/10.1016/j.psychres.2021.113959.

Publisher's Note Springer Nature remains neutral with regard to jurisdictional claims in published maps and institutional affiliations. 